\title{
Antihypertensive and Vasorelaxant effects of the ethanolic extract from the stem bark of Aspidosperma tomentosum Mart
}

\author{
Fabíola Fialho Furtado ${ }^{1}$, Camilla Pinheiro de Menezes ${ }^{1}$, Vanderson Barbosa Bernardo ${ }^{2}$, Antônio Euzébio Goulart \\ Santana $^{2}$, Marcos José Salvador ${ }^{3}$, João Xavier de Araújo-Júnior ${ }^{2,4}$, Emanuel Tenório Paulino ${ }^{4}$, Jessyka Carolina Galvão \\ da Silva ${ }^{4}$, Êrica Adélia Nogueira Ribeiro ${ }^{4 *}$, Isac Almeida de Medeiros ${ }^{1}$

\footnotetext{
${ }^{1}$ Programa de Pós-Graduação em Produtos Naturais e Sintéticos Bioativos, CCS, Universidade Federal da Paraíba, João Pessoa, PB, Brazil. ${ }^{2}$ Instituto de Química e Biotecnologia, Universidade Federal de Alagoas, Maceió, Brazil.

${ }^{3}$ Curso de Farmácia, BTPB, Departamento de Biologia Vegetal, Instituto de Biologia, Universidade Estadual de Campinas, Campinas, Brazil.

${ }^{4}$ Escola de Enfermagem e Farmácia (ESENFAR), Universidade Federal de Alagoas, Maceió, Brazil.
}

\begin{tabular}{l} 
ARTICLE INFO \\
\hline Article history: \\
Received on: $23 / 05 / 2017$ \\
Accepted on: $23 / 09 / 2017$ \\
Available online: $30 / 10 / 2017$ \\
\hline Key words: \\
Aspidosperma tomentosum, \\
vasorelaxant activity, \\
mesenteric rings, Ca ${ }^{2+}$ influx, \\
antihypertensive effect, rats.
\end{tabular}

\begin{abstract}
Aspidosperma species have been traditionally used for the treatment of cardiovascular disease. These species are important sources of indole alkaloids, which are responsible for different cardiovascular effects. Based on this premise, and as there are still no studies related to the cardiovascular effects of the ethanolic extract from the stem bark of Aspidosperma tomentosum (EEAT). The goal of the survey was to characterize the mechanism of the vasorelaxant action of EEAT in isolated rat mesenteric rings and to establish its antihypertensive activity. The mean arterial pressure (MAP) and Heart Rate (HR) were measured in hypertensive rats through a catheter implanted in abdominal aorta via the femoral artery. The vasodilator effect of EEAT in isolated pre-contracted rat mesenteric rings was examined. The bioactive extract was investigated via mass spectrometry fingerprinting. EEAT induced relaxation in mesenteric rings pre-contracted with Phe independent of the endothelium. In denuded rings, when incubation with $\mathrm{KCl} 20 \mathrm{mM}$ or TEA did not change the relaxation. EEAT inhibited the concentration-response curves induced by $\mathrm{CaCl}_{2}$ or Phe and inhibited $80 \mathrm{mM} \mathrm{KCl}$-induced contraction. In precontracted preparations with BayK 8644, the EEAT induced relaxation. The transient contraction induced by Phe was inhibited. The oral administration of EEAT reduced MAP and did not alter the HR. Phenolic acids, flavonoids, and indole alkaloids were identified in EEAT. In conclusion, the EEAT induced vasorelaxation through a blockade of $\mathrm{Ca}^{2+}$ channels and inhibition of the mobilization of $\mathrm{Ca}^{2+}$ of the $\mathrm{IP}_{3}$-sensitive $\mathrm{Ca}^{2+}$ stores and caused an antihypertensive effect.
\end{abstract}

\section{INTRODUCTION}

Hypertension is considerable public health challenge worldwide, affecting $26.4 \%$ of the world's adult population (Kearney et al., 2005).Complications of hypertension are held for 9.4 million deaths worldwide every year (Lim et al., 2012).

\section{* Corresponding Author}

Prof. Dr. Êurica A. N. Ribeiro, Laboratório de Farmacologia Cardiovascular, Escola de Enfermagem e Farmácia (ESENFAR), Universidade Federal de Alagoas, Campus A. C. Simões - Av. Lourival Melo Mota, s/n. Cidade Universitária - 57072-900, Maceió - AL, Brazil. Fax: +55(82)3214-1154,cellular: +55(82)999357698.

E-mail: euricanogueira@gmail.com
Nevertheless, less than $25 \%$ of treated hypertensive patients achieve target mean arterial pressure (MAP) (Evans et al., 2005 ) and, furthermore, $20 \%$ to $30 \%$ of hypertensive individuals may be resistant to antihypertensive treatment (Hajjar et al., 2003). Thus, the search for new, safer and more efficient antihypertensive drugs with fewer side effects is extremely needed (Cogolludo et al., 2005).

The use of medicinal plants is common in patients with cardiovascular disease, including hypertension (Tirapelli et al., 2010). In this context, medicinal plants can be considered as a potential source for new antihypertensive drugs. 
The Aspidosperma genus, which comprises approximately 43 species, is found from Mexico to Argentina (Jacomé et al., 2004). Several Aspidosperma species have been traditionally used for the treatment of cardiovascular diseases, including diabetes, hypercholesterolemia, erectile dysfunction, anti-hyperlipidemic, and also used as a vasodilator (Campos et al., 2006; Tresvenzol et al., 2006; Oliveira et al., 2009). These species are important sources of indole alkaloids, which are responsible for different cardiovascular effects, such as diuretic, hypotensive and $\alpha$-adrenergic receptors blocker (Lyon et al., 1973; Deutsch et al., 1994; Craveiro et al., 1983).

In the literature, there are reports on the cardiovascular effects of Aspidosperma species. For example, in spontaneously hypertensive rats, the ethanolic extract of the wood of Aspidosperma pyrifolium produced hypotensive effects (Herculano et al., 2012). The ethanolic extract of the leaves of Aspidosperma macrocarpum elicited hypotensive, antihypertensive and vasorelaxant effects (Oliveira et al., 2012). The ethanol extract of Aspidosperma subincanum induced hypotension associated with bradycardia and vascular relaxation (Bernardes et al., 2013).

Aspidosperma tomentosum Mart. is a tree commonly recognized in Brazil as "peroba-do-campo". The majority of Aspidosperma species have already been chemically characterized, in which several indole alkaloids were isolated and identified, nevertheless, the pharmacological properties have not yet been largely studied. Based on this premise, and as there are still no studies related to the cardiovascular effects of the ethanolic extract from the stem bark of Aspidosperma tomentosum (EEAT), we aimed to assess the mechanism(s) involved in the vasorelaxant effect of EEAT in rat mesenteric rings, and to establish its antihypertensive activity in vivo.

\section{MATERIALS AND METHODS}

\section{Acquisition and extraction of herbal materials}

The stem bark of Aspidosperma tomentosum Mart. was collected in Planaltina (Goiás/Brazil). The plant species was identified by Botanist Prof. José Elias de Paula, of the Vegetal Anatomy Laboratory (Institute of Biology), University of Brasilia (UnB). A voucher specimen (no. UB-3732) was deposited in the Herbarium of UnB.

Dried and powdered plant material (3.64 $\mathrm{kg})$ was extracted with ethanol/water $(1: 9, \mathrm{v} / \mathrm{v}, 20 \mathrm{~L})$ for $96 \mathrm{~h}$ at room temperature. The solvent was removed under reduced pressure to give the crude extract (EEAT, $316.55 \mathrm{~g}$ ).

\section{Evaluation of chemical composition by ESI-MS analysis}

In this study, to characterize and identify the compounds present in the extract, we employ the method by electrospray ionization mass spectrometry (ESI-MS) in the positive and negative ion mode. Capillary and cone voltages were kept at 3.0 $\mathrm{kV}$ and $30.0 \mathrm{~V}$, using a source temperature of $100^{\circ} \mathrm{C}$ and desolvation temperature of $350^{\circ} \mathrm{C}$. The equipment used was the Micromass-Waters Q-TOF mass spectrometer (Waters,
Manchester, England).The data were processed and stored over 60 s. The spectral scan was performed in an interval between $\mathrm{m} / \mathrm{z}, 100$ and 1000. ESI-MS was conducted by direct infusion. The flow rate was standardized in $10 \mu \mathrm{Lmin}^{-1}$. The equipment used was a syringe pump (Harvard Apparatus, MA, USA). The identification of compounds was made by comparing the ESI-MS/MS fragmentation spectra with fragmentation spectra of the pattern samples and with literature results.

\section{Chemicals and drugs}

Acetylcholine chloride (ACh), BAYK-(-) 8644, caffeine, L-phenylephrine chloride (Phe), tetraethylammonium (TEA) were purchased from Sigma (Sigma Chemical Co., St. Louis, MO, USA). The extract was solubilized in cremofor ${ }^{\circledR}(3 \%)$ and diluted with water to obtain the concentration $10 \mathrm{mg} / \mathrm{mL}$. The final

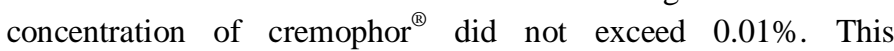
concentration did not induce any effects on the mesenteric artery rings (data not shown). The other compounds were dissolved in distilled water.

\section{Animals}

Male spontaneously hypertensive rats (SHR) and Wistar rats with 12 weeks old were used in all the experimental protocols. The animals came from central bioterium of the UFPB. The SHR and Wistar rats were kept in plastic cages ( 5 rats per cage), under conditions of temperature control and they were subjected to $12 \mathrm{~h}$ $12 \mathrm{~h}$ light-dark cycle, without restriction of feed and tap water. All experimental protocols and techniques performed in this study were accepted by the Institutional Animal Care and Use Committee of the UFPB (Number of the certification 0106/08).

\section{Pharmacological Evaluation \\ Isolated mesenteric ring studies}

The animal was anesthetized and euthanized. The abdominal incision was then performed, and the superior mesenteric artery was removed. The connective and adipose tissues were carefully dissected of the artery. After this procedure, the mesenteric artery was cut into rings of 1-2 $\mathrm{mm}$. The rings were suspended on cotton threads in isolated organ baths filled with $10 \mathrm{~mL}$ of Tyrode's solution (in $\mathrm{mM}$ ): sodium chloride $(\mathrm{NaCl}$ $158.3)$; potassium chloride $(\mathrm{KCl} 4.0)$; calcium chloride $\left(\mathrm{CaCl}_{2}\right.$ 2.0); magnesium chloride $\left(\mathrm{MgCl}_{2}\right.$ 1.05); sodium bicarbonate $\left(\mathrm{NaHCO}_{3} 10.0\right)$; sodium phosphate $\left(\mathrm{NaH}_{2} \mathrm{PO}_{4} \quad 0.42\right)$ and Glucose 5.6 , at $37{ }^{\circ} \mathrm{C}$ and bubbled with carbogenic mixture $\left(95 \% \mathrm{O}_{2}\right.$ and $5 \% \mathrm{CO}_{2}$ ). The mesenteric rings were subjected to a constant tension of $0.75 \mathrm{~g}$ for a period of $60 \mathrm{~min}$.

For this period, the preparations were washed with Tyrode's solution every $15 \mathrm{~min}$ to prevent interference of metabolites. The isometric tension was determined by use ofa force transducer (FORT-10, WPI, Sarasota, FL, USA) connected to an amplifier (Miobath- 4, WPI, Sarasota, FL, USA).

The vascular endothelium was removed by rubbing the intimal surface of the artery with stainless steel rod. The functionality of the endothelium was verified by the relaxation 
induced by acetylcholine ( $\mathrm{ACh}, 10 \mu \mathrm{M})$ in pre-contracted rings with Phe $(10 \mu \mathrm{M})$. Relaxation equal to or greater than $90 \%$ induced by $\mathrm{ACh}$ was considered that the mesenteric rings had functional endothelium, while the mesenteric rings with the relaxation of less than $10 \%$ were considered without vascular endothelium.

\section{Effect of EEAT on the contraction induced by phenylephrine or $\mathrm{KCl}$}

In the first set of experiments, after stabilization for 1 hour, contractions were induced by Phe $10 \mu \mathrm{M}$ in rings with and without vascular endothelium. Then, the extract was added cumulatively (ranging from 0.03 to $300 \mu \mathrm{g} / \mathrm{mL}$ ) to obtain a concentration-response curve. The capability of EEAT to reduce the $80 \mathrm{mM} \mathrm{KCl}$ induced sustained contraction was also verified in rings without endothelium.

\section{Investigation of the role of $\mathrm{K}^{+}$channels in the EEAT-induced vasorelaxant response}

In another set of experiments, rings without endothelium were obtained with $20 \mathrm{mM} \mathrm{KCl}$, an inhibitor of $\mathrm{K}^{+}$efflux, plus Phe or TEA $(3 \mathrm{mM})$, a nonselective blocker of $\mathrm{K}^{+}$channels. Thus, concentration-response curves to EEAT were acquired. The TEA was incubated for $30 \mathrm{~min}$ before the contractions with Phe.

\section{Effect of EEAT on the concentration-response curve for $\mathbf{C a C l}_{2}$}

After removal of endothelium, the mesenteric artery rings were washed for $15 \mathrm{~min}$ in nominally $\mathrm{Ca}^{2+}$-free Tyrode's solution. After this time, the preparations were exposed to the solution of 60 $\mathrm{mM} \mathrm{KCl}$ nominally without calcium for $15 \mathrm{~min}$. Then, cumulative concentration-response curves for $\mathrm{CaCl}_{2}$ were induced. Different concentrations of the EEAT $(10,30,50,100$ or $300 \mu \mathrm{g} / \mathrm{mL})$ were pre-incubated for $15 \mathrm{~min}$. Soon after, new cumulative concentration-response curves for $\mathrm{CaCl}_{2}$ were determined.

\section{Effect of EEAT on the contraction induced by S-(-) BayK 8644}

The rings without endothelium were pre-incubated with $20 \mathrm{mM}$ of the $\mathrm{KCl}$ in Tyrode's solution. After, rings were contracted with (S)-(-)-Bay K $8644\left(10^{-7} \mu \mathrm{M}\right)$ and EEAT was added cumulatively (ranging from 0.03 to $300 \mu \mathrm{g} / \mathrm{mL}$ ).

\section{Effect of EEAT on $\mathrm{Ca}^{2+}$ release from intracellular stores sensitive to phenylephrine and caffeine}

The mesenteric artery rings without endothelium were pre-contracted with $60 \mathrm{mM} \mathrm{KCl}$. After this procedure, the preparations were washed with $\mathrm{Ca}^{2+}$-free Tyrode's solution containing ethylene glycol-bis (2-aminoethyl ether)- $N, N, N^{\prime},{ }^{\prime}$ tetraacetic acid (EGTA $1 \mathrm{mM}$ ) for 2-3 min. After this time interval, phenylephrine $(10 \mu \mathrm{M})$ or caffeine (CAF $20 \mathrm{mM})$ was then added to the organ baths to contract the rings. The contractions induced by phenylephrine or caffeine were obtained in the absence (control) or after incubation with isolated concentrations of the EEAT $(10,30,100$ or $300 \mu \mathrm{g} / \mathrm{mL})$.

\section{Antihypertensive activity}

The measurements of the MAP and HR were performed in SHR rats. The SHR rats were randomly divided into two groups (5 animals per cage), which were denominated of control rats (Saline group) and treated rats (Treated group). The first group received saline and second group a single intragastric dose of 200 $\mathrm{mg}$ of EEAT $/ \mathrm{kg}$ body weight. For measurements of the MAP and HR, the SHR rats were anesthetized with sodium thiopental (45 $\mathrm{mg} / \mathrm{kg}$, i.p.) and polyethylene (PE) catheter was implanted into the lower abdominal aorta via the left femoral artery. Then, the catheter was fixed, filled with a heparin solution, and tunneled subcutaneously to exit between the scapulae. The rats were placed in individual cages and $24 \mathrm{~h}$ after the surgical procedure the MAP and HR were measured.The measurements of the MAP and HR were performed are described above. They were acquired before and after the treatment with EEAT at $0,1,2,4$, and $6 \mathrm{~h}$. The animals were kept in acclimation period of at least $30 \mathrm{~min}$ for stabilization of hemodynamic parameters. Percent decrease in MAP and HR were calculated.

\section{Statistical analysis}

Two pharmacological parameters were used to analyze the data, the $E_{\max }$ (maximum effect elicited by the agonist) and $\mathrm{EC}_{50}$. All values are displayed as the mean \pm standard error of the mean (SEM, $\mathrm{n}=$ number of experiments). The drug concentration that is capable of inhibiting the contractile response by $50 \%\left(\mathrm{EC}_{50}\right)$ was obtained by non-linear regression. Student's t-test or two-way analysis of variance (ANOVA) were used to analyze the results statistically. The differences between the mean were considered significant when the value obtained for "p" was lower than 0.05 (p $<0.05)$.All statistical analysis and plotting of the curves were performed by GraphPad Prism ${ }^{\mathrm{TM}}$ software, version 3.0 (GraphPad Software, Inc., San Diego, CA, USA).

\section{RESULTS}

\section{Analysis of the chemical constituents by ESI-MS}

Using direct infusion electrospray ionization mass spectrometry (ESI-MS/MS) data in the negative and positive ion mode, the ethanol:water (1:9, v/v) extract from the stem bark of $A$. tomentosum were characterized. These analyses demonstrated that the detected constituents in EEAT were equivalent to the mass of the phenolic acids, flavonoids and indole alkaloids (Table 1, Figure 1).

Thus, 10 compounds were tentatively identified (caffeic acid, quinic acid, kaempferol, quercetin, isorhamnetin, dimethyluleine, uleine, aparicine, and quebrachamine) based on CID experiments of the observed precursors and make a comparison of the ESI-MS/MS fragmentation spectra with the spectra of the standard samples, and with literature results. ESI-MS is a technique simple to execute. The sample preparation and the process of acquisition of spectra were performed for $5 \mathrm{~min}$, and it provides valuable information about the constituents present in the extract 
Table 1: Compounds identified in ethanol:water (1:9, v/v) extract from stem bark of Aspidosperma tomentosum (EEAT) using ESI-MS/MS analyses.

\begin{tabular}{|c|c|c|c|}
\hline \multirow[t]{2}{*}{ Detected Compound } & \multicolumn{3}{|c|}{ ESI-MS ions $(\mathrm{m} / \mathrm{z})$} \\
\hline & Deprotonated íons [M-H $]^{\top} m / z$ & Protonated íons $[\mathrm{M}+\mathrm{H}]^{+} m / z$ & MS/MS ions $m / z$ \\
\hline Malic acid & 133 & & $15 \mathrm{eV}: 133 \rightarrow 115$ \\
\hline Caffeic acid & 179 & & $15 \mathrm{eV}: 179 \rightarrow 161,125$ \\
\hline Quinic acid & 191 & & $25 \mathrm{eV}: 191 \rightarrow 173,127,111,93,85$ \\
\hline Kaempferol & 285 & & $15 \mathrm{eV}: 285 \rightarrow 257,299,199,151$ \\
\hline Quercetin & 301 & & $15 \mathrm{eV}: 301 \rightarrow 273,257,179,151$ \\
\hline Isorhamnetin & 315 & & $15 \mathrm{eV}: 315 \rightarrow 300,271$ \\
\hline Demethyl-uleine & & 252 & $15 \mathrm{eV}: 252 \rightarrow 237,223,209,194,180,167$ \\
\hline Uleine & & 266 & $15 \mathrm{eV}: 266 \rightarrow 251,237,223,209,194,180,167$ \\
\hline Aparicine & & 264 & $15 \mathrm{eV}: 264 \rightarrow 251,237,223,209,194,180,167$ \\
\hline Quebrachamine & & 282 & $15 \mathrm{eV}: 282 \rightarrow 253,210,157,138,125,110,96$ \\
\hline
\end{tabular}
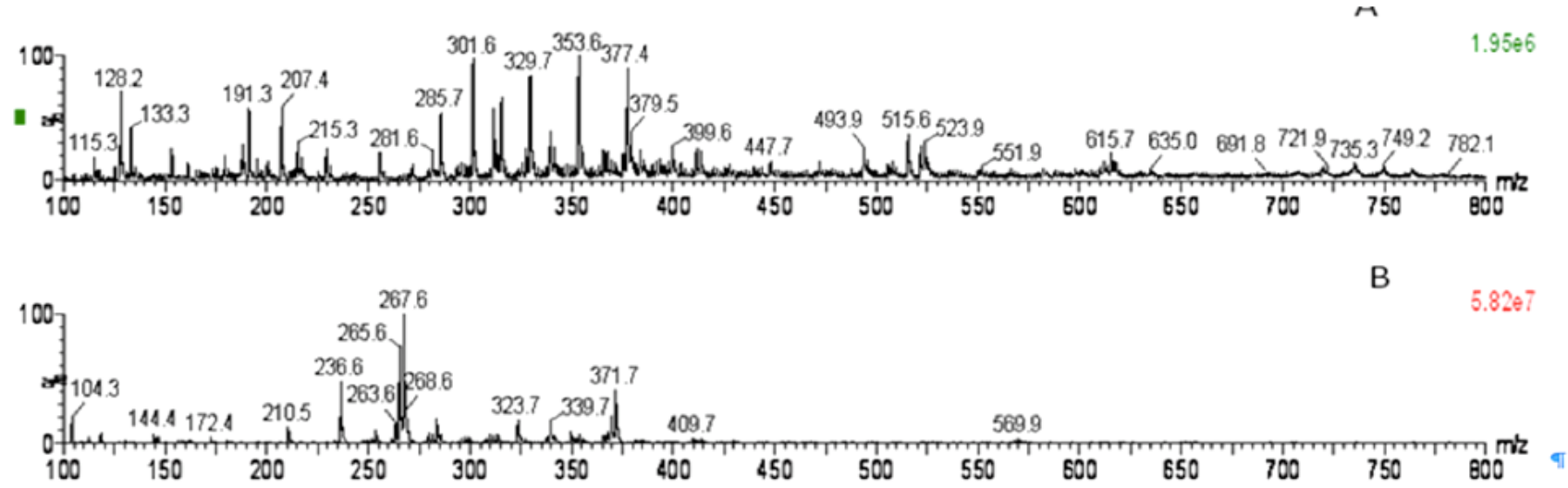

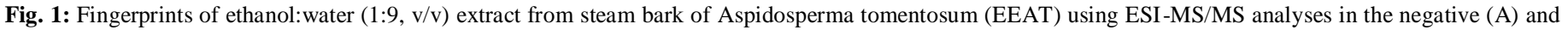
positive (B) ion mode.

\section{Effect of EEAT on the contraction induced by phenylephrine or $\mathrm{KCl}$}

As shown in Table 2, EEAT (0.03 to $300 \mu \mathrm{g} / \mathrm{mL})$ induced relaxation in rat superior mesenteric artery rings in a concentration-dependent manner of Phe-induced tonus. The concentration-response curve to EEAT was not significantly shifted to right without a reduction in the maximal response after endothelium removal.

Table 2: $\mathrm{E}_{\max }$ and $\mathrm{EC}_{50}$ values of experiments in the presence of EEAT.

\begin{tabular}{ccc}
\hline Experiments & $\mathbf{E}_{\max }, \boldsymbol{\%}$ & $\mathbf{E C}_{\mathbf{5 0}}, \boldsymbol{\mu g} / \mathbf{m L}$ \\
\hline Phe with endothelium & $97.0 \pm 4.0$ & $37.1 \pm 4.7$ \\
Phe without endothelium & $99.0 \pm 3.6$ & $32.9 \pm 3.2$ \\
80 mM KCl & $94.4 \pm 4.5$ & $26.4 \pm 3.1$ \\
After 20 mM KCl & $100.0 \pm 3.6$ & $37.4 \pm 8.4$ \\
After TEA & $112.2 \pm 6.4$ & $37.9 \pm 3.8$ \\
\hline
\end{tabular}

Phe, Phenylephrine. TEA, tetraethylammonium. $\mathrm{E}_{\max }$, Maximal relaxation. $\mathrm{EC}_{50}$, the drug concentration inhibiting the contractile response by $50 \% . n=8$.

In rings without endothelium, precontracted with a depolarizing agent $\mathrm{KCl} 80 \mathrm{mM}$, the cumulative addition of EEAT (0.03-300 $\mu \mathrm{g} / \mathrm{mL})$ induced a concentration-dependent vasorelaxant effect with $\left[\mathrm{EC}_{50}=26.4 \pm 3.1 ; \mathrm{E}_{\max }=(94.4 \pm 4.5 \%)\right]$ (Table 2).

\section{Evaluation of the role of $\mathrm{K}^{+}$channels in the EEAT-produced vasorelaxant effect}

In endothelium-denuded rings pre-incubated with $20 \mathrm{mM}$ $\mathrm{KCl}$ and contracted with Phe $(10 \mu \mathrm{M})$, EEAT induced a vasorelaxant effect with no change as compared with control with Phe. The incubation with TEA $(3 \mathrm{mM})$, the concentration-response curves of EEAT not was significantly affected(Table 2).

Effect of EEAT on the concentration-response curve for $\mathrm{CaCl}_{2}$

As showed in the Table 2, in endothelium-denuded rings incubating with depolarizing and nominally without $\mathrm{Ca}^{2+}$ solution, $\mathrm{CaCl}_{2}(1 \mu \mathrm{M}-30 \mathrm{mM})$ was able to induce contractions that were significantly inhibited by EEAT in concentrations of 30, 50, 100 or $300 \mu \mathrm{g} / \mathrm{mL}$ (maximal inhibition $=79.6 \pm 5.2 * ; 64.0 \pm 7.0 * * * ; 22.7$ \pm 4.7 and $13.1 \pm 2.2 \% * * *$; respectively; two-way ANOVA with Bonferroni post-test. $* * \mathrm{p}<0.01, * * * \mathrm{p}<0.001)$.

Effect of EEAT on the contraction induced by S-(-) BayK 8644 As showed in the Figure 3, EEAT $(0.03-300 \mu \mathrm{g} / \mathrm{mL})$ induced relaxation in rat superior mesenteric artery rings in a concentration-dependent manner of S-(-) BayK 8644-induced tonus $\left[\mathrm{CE}_{50}=34.6 \pm 4.5 ; \mathrm{E}_{\max }=(100.0 \pm 4.4 \%)\right]$. 


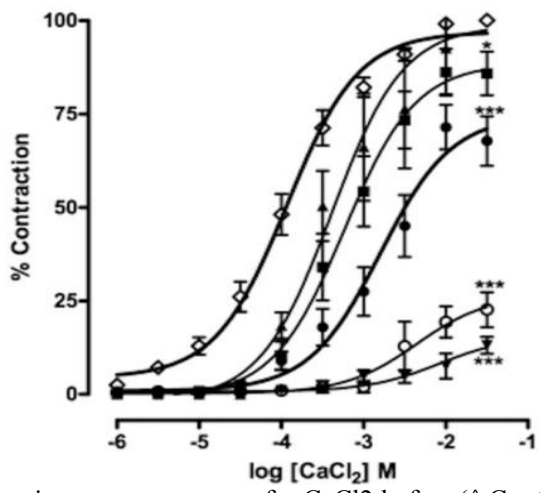

Fig. 2: Concentration-response curves for $\mathrm{CaCl} 2$ before $(\diamond \mathrm{Control}, \mathrm{n}=12)$ and after the incubation of preparations with EEAT $(\Delta 3 \mu \mathrm{g} / \mathrm{mL} \mathrm{n}=6),(-30$ $\mu \mathrm{g} / \mathrm{mL}, \mathrm{n}=8),(\bullet 50 \mu \mathrm{g} / \mathrm{mL}, \mathrm{n}=6),(\circ 100 \mu \mathrm{g} / \mathrm{mL}, \mathrm{n}=5)$ or $(\boldsymbol{\nabla} 300)$

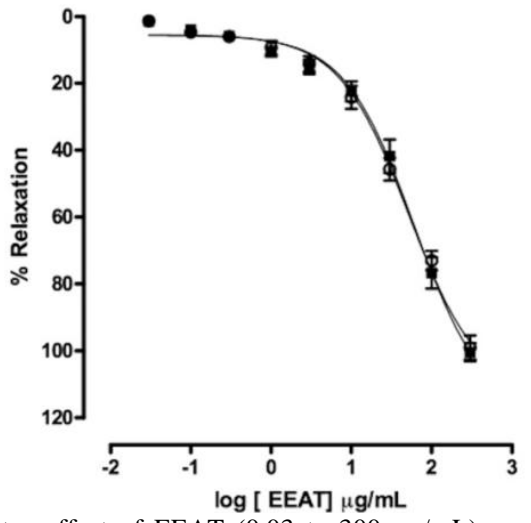

Fig. 3: Vasodilator effect of EEAT (0.03 to $300 \mu \mathrm{g} / \mathrm{mL})$ on phenylephrineinduced contractions $(10 \mu \mathrm{M})$ without functional endothelium $(\mathrm{O}, \mathrm{n}=8)$ and BAYK 8644 induced contractions $(200 \mathrm{nM})(\boldsymbol{m}, \mathrm{n}=8)$. Values are mean \pm s.e.m.

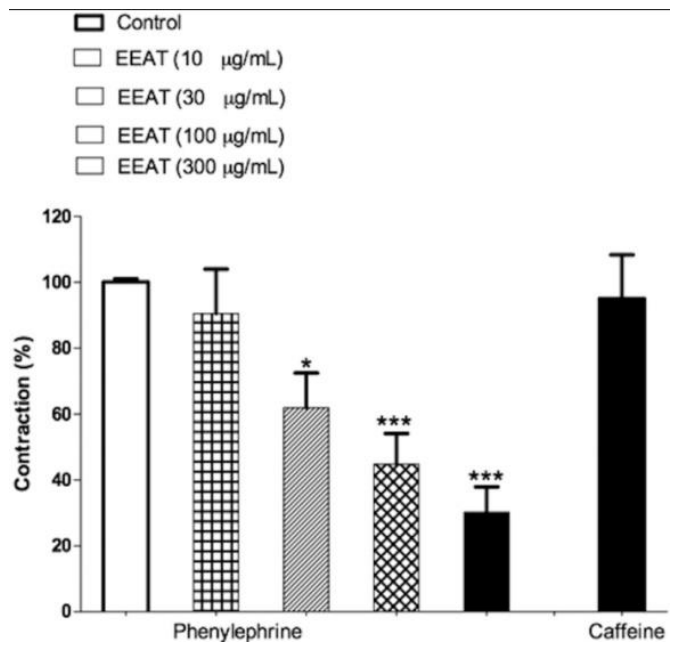

Fig. 4: Effect of EEAT on the contractions induced by phenylephrine (Phe 10 $\mu \mathrm{M})$ or Caffeine $(2 \mathrm{mM})$ in $\mathrm{Ca} 2+$-free Tyrode solution. Contraction is reported as the percentage of the maximal contractile response induced by each vasoconstrictor in the control. Values are mean \pm s.e.m. $(n=8)$.

$* \mathrm{p}<0.05, * * * \mathrm{p}<0.001$ vs control group.

\section{Effect of EEAT on $\mathrm{Ca}^{2+}$ release from intracellular stores sensitive to phenylephrine and caffeine}

As illustrated in Figure 4, in the $\mathrm{Ca}^{2+}$-free solution, the EEAT (30, 100 and $300 \mu \mathrm{g} / \mathrm{mL}$ ) was able to inhibit in a concentration-dependent manner the transient contractions induced by Phe $(10 \mu \mathrm{M})$, and there was no significant change in caffeineinduced contraction (CAF $20 \mathrm{mM}$ ).

\section{Antihypertensive activity of EEAT in SHR}

In this battery of experiments, baseline MAP and HR values were registered at $0 \mathrm{~h}$ and assuming as $100 \%$ of activity. After 1 and $2 \mathrm{~h}$ of extract administration, the MAP was significantly decreased without changed HR when compared the saline group. Nevertheless, after this time, pressure values returned to baseline (Figure 5).

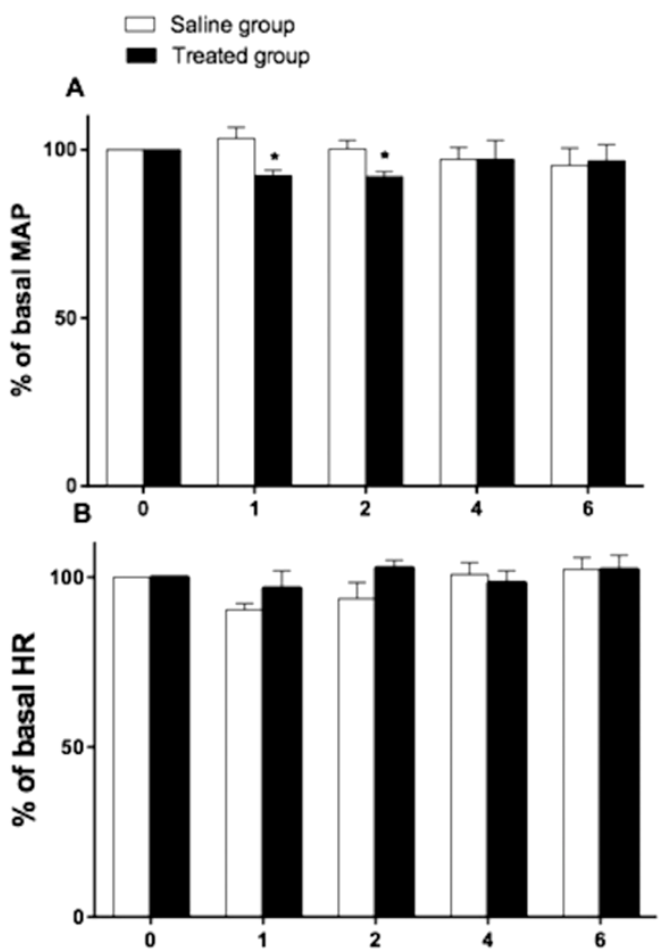

Fig. 5: Effects of EEAT on MAP (A) and HR (B) after of administration of saline (Saline group) and EEAT (200 mg/kg, v.o.) (Treated group). Values are mean \pm s.e.m. of five experiments. $* \mathrm{p}<0.05$ vs saline group.

\section{DISCUSSION}

The main finding in this paper is that the extract induced a vasorelaxant activity in mesenteric rings and the oral administration caused a reduction in the mean arterial pressure in non-anesthetized SHR.

To investigate the direct effect of EEAT on the vasculature, we performed experiments in rat isolated superior mesenteric arteries. This artery was used because it has greater resistance to blood flow. Therefore, it is widely involved in regulating blood pressure (Mulvany and Aalkjaer, 1990). We found that EEAT concentration-dependently induced relaxation in mesenteric rings with or without functional endothelium precontracted with phenylephrine. The $E_{\max }$ and $\mathrm{EC}_{50}$ values of EEAT were not statistically different. Thus, it suggests that the vasorelaxant effect of EEAT is independent of endothelium and this effect is probably due to a direct action of the extract in 
vascular smooth muscle. The $\mathrm{K}^{+}$channels contribute to the regulation of vascular tone. The activation of these channels induces vasorelaxation by membrane hyperpolarization, due to inactivation of voltage-dependent $\mathrm{Ca}^{2+}$ channels and consequently decrease in intracellular $\mathrm{Ca}^{2+}$ levels. In contrast, inhibition of $\mathrm{K}^{+}$ channels function leads to membrane depolarization and vasoconstriction. The potassium channels present in the vascular smooth muscle were four types: voltage-dependent $\mathrm{K}^{+}\left(\mathrm{K}_{\mathrm{v}}\right)$ channels, $\mathrm{Ca}^{2+}$-activated $\mathrm{K}^{+}\left(\mathrm{BK}_{\mathrm{Ca}}\right)$ channels, ATP-sensitive $\mathrm{K}^{+}$ $\left(\mathrm{K}_{\mathrm{ATP}}\right)$ channels, and inward rectifier $\mathrm{K}^{+}$(Kir) (Nelson and Quayle, 1995). To verify the participation of the $\mathrm{K}^{+}$channels in the relaxant response induced by the extract, we executed experiments in the presence partial inhibitor of $\mathrm{K}^{+}$efflux, as the solution 20 $\mathrm{mM} \mathrm{KCl}$. According to the literature, the drugs that induce relaxation by opening $\mathrm{K}^{+}$channels are less efficient in the presence of high external concentration of $\mathrm{K}^{+}$(Campbell et al., 1996).In denuded rings, the incubation with $\mathrm{KCl} 20 \mathrm{mM}$ did not change the relaxation when compared with those obtained in denuded rings, suggesting no involvement of $\mathrm{K}^{+}$channels in this response. To confirm this hypothesis, the endothelium-denuded rings were pretreated with TEA $(3 \mathrm{mM})$, a non-selective blocker of $\mathrm{K}^{+}$ channels. The concentration-response curves of EEAT were not significantly affected, indicating the lack of participation of $\mathrm{K}^{+}$ channels in the vasorelaxant action induced by this extract.

Phenylephrineis an $\alpha_{1}$-adrenergic receptor agonist. The contractions induced by adrenergic agonists in the vascular smooth muscle are initiated by the release of calcium from intracellular $\mathrm{IP}_{3}$ receptor-sensitive stores. The increase in intracellular calcium concentration causes the activation of $\mathrm{Ca}^{2+}$-activated channels and consequently depolarisation (Criddle et al., 1996). On the other hand, the contractions induced by $80 \mathrm{mM} \mathrm{KCl}$ are caused almost completely through the opening of $\mathrm{Ca}_{\mathrm{v}}$ (Karaki et al., 1997).

Therefore, it was evaluated the effect of the extract in rat mesenteric rings precontracted by depolarizing solution of $80 \mathrm{mM}$ $\mathrm{KCl}$. Operating in this conditions, EEAT promoted concentrationdependent relaxation in mesenteric artery rings. It is important to mention that EEAT was able to inhibit both $\mathrm{KCl}$-induced and phenylephrine-induced contractions similarly. These results suggest that the EEAT probably acts by inhibiting $\mathrm{Ca}^{2+}$ influx via $\mathrm{Ca}_{\mathrm{v}}$. According to the literature, two types of $\mathrm{Ca}^{2+}$ channels are expressed in smooth muscle cells: voltage-dependent $\mathrm{Ca}^{2+}$ channels (high $\mathrm{KCl}$ induced contraction is due to membrane depolarization, consequently increasing the $\mathrm{Ca}^{2+}$ influx through these channels) and receptor operated $\mathrm{Ca}^{2+}$ channels (contraction induced by Phe or CAF is due to intracellular $\mathrm{Ca}^{2+}$ release, through sarcoplasmic reticulum $\mathrm{Ca}^{2+}$ channels activated by $\mathrm{IP}_{3}$ or ryanodine) (Clapham, 2007). The extract inhibited contractions induced by phenylephrine or $\mathrm{KCl}$ in endothelium-denuded mesenteric rings. Analyzing the results obtained with EEAT, we can suggest that the vasorelaxant mechanism may involve blocking both voltage-dependent and receptor operated $\mathrm{Ca}^{2+}$ channels. Furthermore, in endothelium-denuded rings incubating with depolarizing and nominally without $\mathrm{Ca}^{2+}$ solution, $\mathrm{CaCl}_{2}(1$ $\mu \mathrm{M}-30 \mathrm{mM}$ ) was able to induce contractions that were significantly inhibited by EEAT, supporting the idea that EEAT possesses a $\mathrm{Ca}^{2+}$ influx blocking activity. In order to evaluate the $\mathrm{Ca}_{\mathrm{v}}$ subtype involved in the inhibition of $\mathrm{Ca}^{2+}$ influx promoted by the EEAT, we perform experiments with S-(-)-Bay K8644, an Ltype $\mathrm{Ca}_{\mathrm{v}}$ agonist (Spedding and Paoletti, 1992). EEAT induced relaxation in rat superior mesenteric artery rings in a concentration-dependent manner of S-(-) BayK 8644-induced tonus. Our results suggest that the EEAT probably decreases the calcium influx via L-type channel. Further studies involving voltage-dependent $\mathrm{Ca}^{2+}$ currents in the smooth muscle cell are needed to confirm the participation of L-type voltage-gated calcium channels (VGCC) in EEAT-induced relaxation. However, in the $\mathrm{Ca}^{2+}$-free solution, EEAT significantly inhibited the Phe (10 $\mu \mathrm{M})$-induced contraction in a concentration-dependent manner. EEAT $(300 \mu \mathrm{g} / \mathrm{mL})$ did not inhibit transient contractions induced by caffeine $(20 \mathrm{mM})$ in a $\mathrm{Ca}^{2+}$ - free solution containing EGTA. This result suggests that EEAT may also inhibit $\mathrm{Ca}^{2+}$ mobilization from intracellular stores by a possible $\mathrm{IP}_{3}$ signaling blockade.

The different effects mentioned in this study were unlikely caused by toxicity of EEAT on vascular cells. We can make this affirmation because the relaxant effect induced by extract was reproduced, and the contraction induced by Phe was completely restored following a $60 \mathrm{~min}$ of EEAT.

Literature data confirm that the essential hypertension is in part determined by genetic factors. The SHR are models of animals that develop hypertension of genetic origin. Based on this premise, they were used to analyze the antihypertensive effect of the extract. The intragastric administration of EEAT in nonanesthetized SHR induced reduction significant in MAP (first and second hours after oral administration of the extract) and did not change the heart rate. Nevertheless, after this time, pressure values returned to baseline. The effects induced by EEAT on the cardiovascular system in rats are in agreement with literature data, related with bioactivity of Apocynaceae species and with bioactive chemical compounds isolated from species of the Aspidosperma, which are rich alkaloids, including aspidospermine, quebrachamine, and yohimbine (Lyon et al., 1973; Craveiro et al., 1983; Sperling et al., 2002). Also, other natural products have been documented, such as the occurrence of triterpenes (Barbosa et al., 2010), flavonol glycosides, quercetin, kaempferol and isorhamnetin derivatives (Pelotto and Del Pero, 1995) in genus Aspidosperma. The EEAT was analyzed by ESI-MS in the positive and negative ion mode. These analyses showed that the detected constituents in EEAT coincided with the mass of the phenolic acids, flavonoids, and indole alkaloids. Thus, 10 compounds were tentatively identified (caffeic acid, quinic acid, kaempferol, quercetin, isorhamnetin, dimethyl-uleine, uleine, aparicine, and quebrachamine), based on CID experiments of the observed precursors and comparison of their ESI-MS/MS spectra with authentic standard spectra, and with literature data. The experiment performed by ESI-MS provided relevant information about the active principles present in the extract. It is reported that flavonoids such as rutin, quercetin, and apigenin promote vasorelaxation by inhibiting the influx of $\mathrm{Ca}^{2+}$, and flavonoids like 
flavones and flavonols, inhibit the release of $\mathrm{Ca}^{2+}$ from intracellular stores (Chan et al., 2000). The caffeic acid phenethyl ester inhibited contractile responses to phenylephrine or $\mathrm{KCl}$ in thoracic aortic rings, and also inhibited the contractile response to phenylephrine obtained in a $\mathrm{Ca}^{2+}$-free medium (Cicala et al., 2003). Using the ESI-MS technique, it was possible to detect the presence of some phenolic acids, flavonoids and, alkaloids in EEAT. The presence of these bioactive components could explain, in part, the antihypertensive and vasorelaxant action of the extract.

\section{CONCLUSIONS}

Our results suggest that EEAT induces vasorelaxation through a blockade of $\mathrm{Ca}^{2+}$ channels and inhibition of the mobilization of $\mathrm{Ca}^{2+}$ of the $\mathrm{IP}_{3}$-sensitive $\mathrm{Ca}^{2+}$ stores, and also causes an antihypertensive effect. Our findings have highlighted the therapeutic potential of $A$. tomentosum for the treatment of cardiovascular diseases.

Conflict of Interest: The authors declare no conflict of interest.

Financial support: The authors are grateful to CNPq, CAPES, and FAPEAL for the joint funding of this research project.

\section{REFERENCES}

Barbosa LF, Mathias L, Braz-Filho R, Vieira IJC. Chemical constituents from Aspidosperma illustre (Apocynaceae). J Bra Chem Soc. 2010; 21:1434-38.

Bernardes MJC, de Carvalho FS, Lima Silveira L, de Paula JR, Bara MTF, Garrote CF, et al. Hypotensive effect of Aspidosperma subincanum Mart. in rats and its mechanism of vasorelaxation in isolated arteries. J Ethnopharmacol. 2013; 145: 227-32.

Campbell WB, Gebremedhin D, Pratt PF, Harder DR. Identification of epoxyeicosatrienoic acids as endothelium-derived hyperpolarizing factors. Circ Res. 1996; 78: 415-23.

Campos AR, Lima RCP, Uchoa DEA, Silveira ER, Santos FA, Rao VSN. Pro-erectile effects of an alkaloidal rich fraction from Aspidosperma ulei root bark in mice. J Ethnopharmacol. 2006; 104: 24044.

Chan, ECH, Pannangpetch P, Woodman OL. Relaxation to flavones and flavonols in rat isolated thoracic aorta: mechanism of action and structure-activity relationships.J Card Pharmacol. 2000; 35:326-33.

Cicala C, Morello S, Iorio C, Capasso R, Borrelli F, Mascolo N. Vascular effects of caffeic acid phenethyl ester (CAPE) on isolated rat thoracic aorta. Life Sci.2003; 73: 73-80.

Clapham DE. Calcium signaling. Cell. 2007; 131: 1047-1058.

Cogolludo A, Pérez-Vizcaíno F, Tamargo J. New insights in the pharmacological therapy of arterial hypertension. Curr Opin Nephrol Hypertens. 2005; 14: 423-27.

Craveiro AA, Matos FJA, Serur LM. Alkaloids of Aspidosperma pyrifolium. Phytochemistry. 1983;22: 1526-28.

Criddle DN, de Moura RS, Greenwood IA, Large WA. 1996. Effect of niflumic acid on noradrenaline-induced contractions of the rat aorta. Br J Pharmacol. 1996; 118: 1065-71.

Deutsch HF, Evenson MA, Drescher P, Sparwasser C, Madsen PO. Isolation and biological activity of aspidospermine and quebrachamine from an Aspidosperma tree source. J Pharm Biomed Anal. 1994; 12: 1283-87.

Evans RG, Kett MM, Shweta A, Fitzgerald SM, Denton KM, Eppel GA, et al. New Physiological Targets Within the Kidney for Antihypertensive Therapy. Drug Des Rev. 2005; 2: 167-178.
Hajjar I, Kotchen TA. Trends in prevalence, awareness, treatment, and control of hypertension in the United States, 1988-2000. JAMA. 2003; 290: 199-206.

Herculano EA, Costa CDF, Aquino PGV, Sant'ana EG, AraújoJúnior JX, Ribeiro, EAN. Evaluation of Cardiovascular response induced by ethanolic extract of Aspidosperma pyrifolium wood on arterial pressure in spontaneously hypertensive rats. Pharmacologyonline. 2012;1: $16-21$.

Jacomé RLRP, OliveiraAB, Raslan NDS, Wagner H. Chemical constituents and chromatographic profile of the stem bark Aspidosperma parvifolium (Pau-Pereira). Química Nova. 2004; 27: 897-900.

Karaki H, Ozaki H, Hori M, Mitsui-Saito M, Amano K, Harada $\mathrm{K}$, et al. Calcium movements, distribution, and functions in smooth muscle. Pharmacol Rev. 1997; 49: 157-230.

Kearney PM, Whelton M, Reynolds K, Muntner P, Whelton PK, He J. Global burden of hypertension: analysis of worldwide data. Lancet. 2005; 365: 217-23.

Lim SS, Vos T, Flaxman AD, Danaei G, Shibuya K, AdairRohani $\mathrm{H}$, et al. A comparative risk assessment of burden of disease and injury attributable to 67 risk factors and risk factor clusters in 21 regions, 1990-2010: a systematic analysis for the Global Burden of Disease Study 2010. Lancet. 2012; 380: 2224-60.

Lyon RL, Fong HH, Farnsworth NR, Svoboda GH. Biological and phytochemical evaluation of plants. Isolation of aspidospermine, quebrachidine, rhazinilam, (-)-pyrifolidine, and akuammidine from Aspidosperma quebracho-blanco (Apocynaceae). J Pharm Sci. 1973; 62: 218-21.

Mulvany MJ, Aalkjaer C. Structure and function of small arteries. Physiol Rev. 1990; 70: 921-61.

Nelson MT, Quayle JM. Physiological roles and properties of potassium channels in arterial smooth muscle. Am J Physiol. 1995; 268 : 799-822.

Oliveira MP, Costa CDF, Herculano EA, Aquino PG V, Sant'Ana AEG, Ribeiro EAN, et al. Cardiovascular effects of the Aspidosperma macrocarpum leaves ethanol extract in rats. Pharmacologyonline. 2012;1: 102-07.

Oliveira VB, Freitas MSM, Mathias L, Braz-Filho R, Vieira IJC.Atividade biológica e alcalóides indólicos do gênero Aspidosperma (Apocynaceae): uma revisão. Rev Bras Plantas Med. 2009; 11: 92-9.

Pelotto JP, Del Pero MA. Flavonoids from Aspidosperma quebracho-blanco leaves. Fitoterapia. 1995; 66:88.

Spedding M, Paoletti R. Classification of calcium channels and calcium antagonists: progress report. Cardiovasc Drugs Ther. 1992; 6: 35 39.

Sperling H, Lorenz A, Krege S, Arndt R, Michel MC. An extract from the bark of Aspidosperma quebracho blanco binds to human penile alpha-adrenoceptors. J Urol. 2002; 168:160-63.

Tirapelli CR, Ambrosio SR, de Oliveira AM, Tostes RC. Hypotensive action of naturally occurring diterpenes: a therapeutic promise for the treatment of hypertension. Fitoterapia. 2010;81: 690-702.

Tresvenzol LM, Paula JR, Ricardo AF, Ferreira HD, Zatta DT. Estudo sobre o comércio informal de plantas medicinais em Goiânia e cidades vizinhas. Revista Eletrônica de Farmácia. 2006; 3:23-28.

\section{How to cite this article:}

Furtado FF, Menezes CP, Bernardo VB, Santana AEG, Salvador MJ, Araújo-Júnior JX, Paulino ET, Silva JCG, Ribeiro EAN, Medeiros IA. Antihypertensive and Vasorelaxant Effects of the Ethanolic Extract From the Stem Bark of Aspidosperma Tomentosum Mart. J App Pharm Sci, 2017; 7 (10): 118-124. 